\title{
Retrospective study on recovery of 521 gastrointestinal tumor patients after laparoscopic surgery
}

\author{
JIAKUN SHI, SHENGJIE LI, YUJIE WANG and LEI ZHENG \\ Department of Gastrointestinal Surgery, Dalian Central Hospital, Dalian, Liaoning 116033, P.R. China
}

Received October 12, 2017; Accepted June 20, 2018

DOI: $10.3892 / \mathrm{ol} .2018 .9064$

\begin{abstract}
Influencing factors for recovery of patients with gastrointestinal tumor after laparoscopic surgery were explored to promote recovery of patients. Clinical data from 521 gastrointestinal tumor patients who underwent laparoscopic surgery in Dalian Central Hospital were collected. The recovery of gastrointestinal function was recorded, and the factors that affected the recovery of gastrointestinal function were analyzed. All data were processed using Statistical Product and Service Solutions (SPSS) 21.0 software. t-test and F-test were used for univariate analysis, and multivariate linear regression was adopted for multivariate analysis. Results of univariate analysis displayed that age, starting time of postoperative activity, peritoneal drainage tube indwelling time, blood potassium level, sleep disorder, fasting and fluid deprivation time, duration of the first postoperative defecation/exhaustion, abdominal distention and pain reaction and social support level had significant influences on recovery of patients after operation $(\mathrm{P}<0.05)$. Results of multivariate analysis indicated that peritoneal drainage tube indwelling time, blood potassium level, fasting and fluid deprivation time and starting time of postoperative activity were independent factors affecting the recovery of patients after operation $(\mathrm{P}<0.05)$. Some methods are conducive to the recovery of gastrointestinal function in patients with gastrointestinal tumor, including the removal of peritoneal drainage tube, timely potassium supplementation, and diet recovery after laparoscopic surgery as soon as possible.
\end{abstract}

\section{Introduction}

Global burden of cancer is increasing, and China accounts for $>20 \%$ of new cases of cancer. Incidence ( $~ 9.7 \%)$ and mortality of gastric cancer $(\sim 8.8 \%)$ both rank third in the world $(1,2)$. Malignant tumor of the gastrointestinal tract is one of the

Correspondence to: Dr Jiakun Shi, Department of Gastrointestinal Surgery, Dalian Central Hospital, 826 Xinan Road, Dalian, Liaoning 116033, P.R. China

E-mail: ctehes@163.com

Key words: gastrointestinal cancer, laparoscopic surgery, influencing factors, $\mathrm{t}$-test, retrospective study most common types of malignant tumors in China. In recent years, incidence of this disease showed an increasing trend and the onset age is becoming increasingly younger. Patient with gastric cancer are usually treated with radical surgery, adjuvant multidisciplinary teams (MDT) of radiotherapy and chemotherapy $(3,4)$. Besides, the rapid development of minimally invasive techniques has made laparoscopic surgery a main treatment for this disease $(5,6)$. However, prognosis of patients with gastrointestinal cancer is still poor, and the incidence rates of postoperative gastrointestinal tract dysfunction (PGID) and other complications are still high (7). Surgery may cause gastrointestinal dysfunction, which is characterized by hypoactive bowel sound or even disappearance and manifested by nausea and vomiting, hiccup, abdominal pain, abdominal distension, diarrhea, constipation, cease of exhaust and delayed recovery of normal diet (8). Gastrointestinal dysfunction after surgery not only exacerbates the patient's pain, reduce the comfort and hinder the prognosis, but also delay recovery of normal diet of patients, leading to the internal environment disorder and the occurrence of postoperative intestinal adhesions and other complications (2). In addition, sleep disorder and social support are also related to the recovery of gastrointestinal function after gastrointestinal tumor surgery (9). Good prognosis of patients with gastrointestinal cancer not only depends on the successful surgery, but also the recovery of gastrointestinal function and effective control of risk factors closely related to the postoperative recovery.

\section{Patients and methods}

Clinical data. Five hundred and twenty-one malignant gastrointestinal tumor patients (diagnosed by pathological biopsy) who underwent laparoscopic surgery in Dalian Central Hospital (Dalian, China) from January 2014 to January 2016 were enrolled into the study, and the clinical data were retrospectively analyzed. To ensure the reliability of the questionnaire, patients with a history of mental illness or mental disorders and patients with other severe underlying diseases were excluded. Patients with mental illness and mental disorders are not suitable to fill in the questionnaire of patient's self-centered feelings. Occurrence of other severe underlying diseases can affect postoperative recovery. Basic information of 521 patients is listed in Table I. There were 278 males and 243 females, and age range was 23-80 years, with a mean age of 55 years. Among these patients, $72.55 \%$ had a body mass index 
(BMI) $<25 \mathrm{~kg} / \mathrm{m}^{2}$ and $77.54 \%$ of patients were in phase II (10). A total of 143 patients underwent radical gastrectomy, and the scope of the operation was primary lesions and $2 / 3$ of the distal stomach, all large and small omentum, the first part of the duodenum, regional lymph nodes, and the entire infiltrated organ. A total of 244 patients received radical resection for colon cancer, 134 underwent radical resection of rectal cancer for the removal of the tumor and its distal mesorectum and distal intestine $2 \mathrm{~cm}$ from the tumor. Gastrointestinal tract tumors were divided into stage I, stage II and stage III according to Union for International Cancer Control (UICC) tumor-nodemetastasis (TNM) (11) staging established in 2010.

The study was approved by the Ethics Committee of Dalian Central Hospital and informed consents were signed by the patients or their guardians.

Data collection. Questionnaire survey was carried out to assess the sleep, social support, abdominal pain and other indexes. All researchers were trained in the same way. Patients were informed of all the details before they filled in the questionnaire. Other indicators, such as age, TNM staging and blood potassium levels, were obtained from clinical record.

Evaluation indexes. The time from the end of surgery to recovery of bowel sound: The time of the patient's return to ward from operation room was set as the starting time. Abdominal part of patient was divided into four regions, which were auscultated every two hours, 1 min every time for each part. Bowel sound that could be heard in two or more regions for three times or more was regarded as recovery, and the earliest time was set as the time (h) of the recovery of bowel sound. The cut-off values for the indexes were based on Michelet et al (12-15).

The time to the first defecation/exhaustion after operation: The time of the patient's return to the ward from the operation room was set as the starting time. The time of the first evacuation or defecation after operation was recorded by the patients or their families. Abdominal distension and pain scoring: Rome III standard was used as the scoring standard (16).i) Grade 0 (0 point), no abdominal distension; ii) grade I (1 point), mild abdominal distention that cannot affect rest and sleep; there is slight bulge at the abdomen, and the abdominal wall tension is low; iii) grade II (2 points), moderate abdominal distention, nausea and a certain degree of abdominal pain at incision that can affect rest and sleep to some extent; there is moderate bulge at the abdomen, and the abdominal wall tension is increased; and iv) grade III (3 points), severe abdominal distension, nausea and vomiting; the abdominal distension and pain at incision cannot be tolerated, which affect rest and sleep, leading to the poor mental state, even expiratory dyspnea; the abdomen showed obvious bulge, and the abdominal wall tension is high, showing tympany at percussion.

Grading of nausea and vomiting, hiccup and other gastrointestinal reactions (GIR) (16,17): i) grade 0 (0 point), no nausea and vomiting, hiccup and other GIR; ii) grade I (1 point), only nausea and no vomiting of stomach contents; iii) grade II ( 2 points), nausea and vomiting for once or twice; iv) grade III (3 points), nausea and vomiting for at least 3 times.

Sleep quality was evaluated according to Pittsburgh sleep quality index (PSQI) (18). Sleep disorder: $>7$ points, sleep quality is inversely proportional to the score.
Table I. General data of 521 patients

\begin{tabular}{lc}
\hline General data & Case \\
\hline Sex (n, \%) & \\
Male & $278(53.36 \%)$ \\
Female & $243(46.64 \%)$ \\
Average age (mean \pm SD) & $54.92 \pm 13.15$ \\
Range of age (years) & $23-80$ \\
Body mass index (BMI) $(\mathrm{n}, \%)$ & \\
$<25 \mathrm{~kg} / \mathrm{m}^{2}$ & $378(72.55 \%)$ \\
$\geq 25 \mathrm{~kg} / \mathrm{m}^{2}$ & $143(27.45 \%)$ \\
Name of surgery (n, \%) & \\
Radical gastrectomy & $143(27.45 \%)$ \\
Radical resection of & $244(46.83 \%)$ \\
colon carcinoma & $134(25.72 \%)$ \\
Radical resection of & \\
rectal carcinoma & \\
TNM staging (n, $\%)$ & $82(15.74 \%)$ \\
Stage I & $404(77.54 \%)$ \\
Stage II & $35(6.72 \%)$ \\
Stage III &
\end{tabular}

Table II. Postoperative basic conditions of patients.

\begin{tabular}{lc}
\hline Index & \multicolumn{1}{c}{ Value } \\
\hline $\begin{array}{l}\text { Postoperative recovery time of } \\
\text { bowel sound (mean } \pm \text { SD) (h) }\end{array}$ & $28.93 \pm 12.74$ \\
$\begin{array}{l}\text { The time to first exhaustion } \\
\text { after operation (mean } \pm \text { SD) }(h)\end{array}$ & $51.98 \pm 19.21$ \\
$\begin{array}{l}\text { The time to first defecation } \\
\text { after operation (mean } \pm \text { SD) (h) }\end{array}$ & $72.36 \pm 41.02$ \\
$\begin{array}{l}\text { Social support (n, \%) } \\
\text { Less }\end{array}$ & \\
$\quad$ Moderate & $136(26.10 \%)$ \\
$\quad$ Satisfactory & $71(13.63 \%)$ \\
Sleep disorder (n, \%) & $314(60.27 \%)$ \\
$\quad$ Yes & $329(63.15 \%)$ \\
No & $192(36.85 \%)$ \\
\hline
\end{tabular}

Social support was assessed according to the social support revalued scale worked out by Xu et al (19). Less social support, $<24$ points; moderate social support, 24-34 points; satisfactory social support, $>34$ points.

Statistical analysis. All data were processed using Statistical Product and Service Solutions (SPSS) 21.0 software (IBMCorp., Armonk, NY, USA); data are expressed as mean \pm standard deviation (SD). Each measurement was repeated three times, t-test and F-test, multiple linear regression analysis was used for multivariate analysis and ANOVA was adopted for multivariate analysis and the post hoc test was LSD test. $\mathrm{P}<0.05$ was considered to indicate a statistically significant difference. 
Table III. Univariate analysis on recovery of gastrointestinal tumor patients after laparoscopic surgery.

\begin{tabular}{|c|c|c|c|c|c|c|}
\hline Variable & $\begin{array}{l}\text { Case } \\
(\mathrm{n}, \%)\end{array}$ & $\begin{array}{l}\text { Recovery time of } \\
\text { bowel sound } \\
(\text { mean } \pm \mathrm{SD})(\mathrm{h})\end{array}$ & $\begin{array}{l}\text { The first exhaust } \\
\text { time after operation } \\
(\text { mean } \pm \text { SD) }(h)\end{array}$ & $\begin{array}{l}\text { The first defecation } \\
\text { time after operation } \\
(\text { mean } \pm \text { SD) }(h)\end{array}$ & $\begin{array}{l}\text { Abdominal } \\
\text { distention } \\
\text { and pain score }\end{array}$ & $\begin{array}{l}\text { GIR } \\
\text { score }\end{array}$ \\
\hline \multicolumn{7}{|l|}{ Age (years) } \\
\hline$<40$ & $41(13.05 \%)$ & $25.95 \pm 9.24$ & $42.43 \pm 14.97$ & $56.23 \pm 23.78$ & $1.03 \pm 0.54$ & $1.29 \pm 0.62$ \\
\hline $40-60$ & $191(36.67 \%)$ & $30.04 \pm 12.27$ & $49.94 \pm 21.46$ & $71.83 \pm 30.42$ & $1.48 \pm 0.74$ & $1.44 \pm 0.73$ \\
\hline$>60$ & $289(55.47 \%)$ & $39.66 \pm 14.21$ & $67.11 \pm 25.43$ & $88.47 \pm 38.55$ & $1.66 \pm 0.62$ & $1.76 \pm 0.82$ \\
\hline F-value & & 12.53 & 15.72 & 21.73 & 6.347 & 7.248 \\
\hline $\mathrm{P}$-value & & 0.01 & 0.01 & $<0.001$ & 0.031 & 0.026 \\
\hline \multicolumn{7}{|c|}{$\begin{array}{l}\text { Starting time of } \\
\text { postoperative activity }\end{array}$} \\
\hline$\leq 3$ days & $383(73.51 \%)$ & $23.94 \pm 9.34$ & $56.23 \pm 30.01$ & $59.34 \pm 29.78$ & $1.23 \pm 0.36$ & $1.38 \pm 0.66$ \\
\hline$>3$ days & $138(26.49 \%)$ & $35.47 \pm 15.63$ & $83.46 \pm 52.17$ & $93.93 \pm 34.72$ & $1.74 \pm 0.77$ & $1.92 \pm 1.77$ \\
\hline F-value & & 8.35 & 7.66 & 9.24 & 4.211 & 5.749 \\
\hline $\mathrm{P}$-value & & $<0.001$ & 0.01 & $<0.001$ & 0.008 & 0.009 \\
\hline \multicolumn{7}{|c|}{$\begin{array}{l}\text { Peritoneal drainage } \\
\text { tube indwelling time }\end{array}$} \\
\hline$\leq 7$ days & $90(17.27 \%)$ & $25.44 \pm 8.75$ & $41.67 \pm 14.83$ & $55.34 \pm 31.56$ & $1.32 \pm 0.73$ & $1.24 \pm 0.71$ \\
\hline$>7$ days & $431(82.73 \%)$ & $35.21 \pm 14.33$ & $56.53 \pm 23.70$ & $77.34 \pm 46.23$ & $1.78 \pm 0.69$ & $1.66 \pm 0.65$ \\
\hline t value & & 4.01 & 3.68 & 2.96 & 5.389 & 3.863 \\
\hline P-value & & 0.02 & 0.02 & 0.03 & 0.021 & 0.042 \\
\hline \multicolumn{7}{|c|}{ Serum potassium level } \\
\hline Abnormal & $141(27.06 \%)$ & $34.32 \pm 14.21$ & $67.28 \pm 22.61$ & $99.34 \pm 43.24$ & $1.74 \pm 0.82$ & $1.93 \pm 0.77$ \\
\hline Normal & $380(72.94 \%)$ & $25.35 \pm 10.33$ & $44.38 \pm 12.63$ & $55.81 \pm 31.87$ & $1.28 \pm 0.58$ & $1.43 \pm 0.68$ \\
\hline $\mathrm{t}$ value & & 11.46 & 16.34 & 16.94 & 3.557 & 5.31 \\
\hline $\mathrm{P}$-value & & $<0.001$ & 0.01 & 0.01 & 0.002 & 0.006 \\
\hline \multicolumn{7}{|l|}{ Sleep disorder } \\
\hline Yes & $340(65.26 \%)$ & $38.29 \pm 14.28$ & $68.92 \pm 21.82$ & $90.28 \pm 34.98$ & $1.86 \pm 0.52$ & $1.87 \pm 0.83$ \\
\hline No & $181(34.74 \%)$ & $24.99 \pm 10.38$ & $39.72 \pm 14.98$ & $53.92 \pm 43.97$ & $1.32 \pm 0.24$ & $1.28 \pm 0.78$ \\
\hline $\mathrm{t}$ value & & 14.38 & 13.84 & 15.39 & 3.297 & 2.982 \\
\hline $\mathrm{P}$-value & & $<0.001$ & $<0.001$ & $<0.001$ & 0.002 & 0.006 \\
\hline \multicolumn{7}{|c|}{$\begin{array}{l}\text { Postoperative fasting } \\
\text { and fluid deprivation time }\end{array}$} \\
\hline$\leq 5$ days & $329(63.15 \%)$ & $23.76 \pm 9.83$ & $43.87 \pm 17.72$ & $55.82 \pm 30.82$ & $1.14 \pm 0.67$ & $1.37 \pm 0.72$ \\
\hline$>5$ days & $192(36.85 \%)$ & $41.27 \pm 14.24$ & $68.82 \pm 25.23$ & $98.37 \pm 44.82$ & $1.75 \pm 0.72$ & $1.81 \pm 0.79$ \\
\hline $\mathrm{t}$ value & & 7.48 & 8.38 & 9.32 & 2.842 & 1.974 \\
\hline P-value & & $<0.001$ & $<0.001$ & 0.01 & 0.006 & 0.039 \\
\hline \multicolumn{7}{|c|}{ Social support level } \\
\hline Less & $136(26.10 \%)$ & $43.76 \pm 15.37$ & $83.21 \pm 24.27$ & $110.26 \pm 44.28$ & $1.97 \pm 0.83$ & $2.18 \pm 0.88$ \\
\hline Moderate & $71(13.63 \%)$ & $37.21 \pm 10.42$ & $46.39 \pm 18.32$ & $71.38 \pm 40.28$ & $1.46 \pm 0.62$ & $1.63 \pm 0.71$ \\
\hline Satisfactory & $314(60.27 \%)$ & $23.82 \pm 7.48$ & $34.34 \pm 10.28$ & $45.32 \pm 32.76$ & $1.02 \pm 0.46$ & $1.12 \pm 0.68$ \\
\hline F-value & 72.33 & 93.82 & 109.28 & 113.82 & 32.918 & 21.973 \\
\hline P-value & $<0.001$ & $<0.001$ & 0.01 & 0.01 & 0.002 & 0.015 \\
\hline
\end{tabular}

ANOVA was used to compare age and social support.t-test was used to compare the time of postoperative activity, the duration of intraperitoneal drainage tube indwelling, the level of blood potassium, the condition of sleep disorder and the duration of fasting water. GIR, gastrointestinal reactions.

\section{Results}

Postoperative basic conditions of five hundred and twenty-one patients. Recovery time of bowel sounds was $28.93 \pm 12.74 \mathrm{~h}$; time of the first exhaust was $51.98 \pm 19.21 \mathrm{~h}$; time of the first defecation was $72.36 \pm 41.02 ; 60.27 \%$ of patients showed satisfactory social support, and $26.10 \%$ of patients complained that they did not receive enough social support. Sleep disorders occurred in 329 patients (Table II).

Univariate analysis on recovery of gastrointestinal tumor patients after laparoscopic surgery. As shown in Table III, recovery time of bowel sound, the time to the first postoperative defecation/exhaustion after operation were shortened, and 
Table IV. Multivariate analysis on recovery time of bowel sound of gastrointestinal tumor patients after laparoscopic surgery.

\begin{tabular}{|c|c|c|c|c|c|c|}
\hline Variable & $\begin{array}{l}\text { Regression } \\
\text { coefficient }\end{array}$ & $\begin{array}{l}\text { Standard } \\
\text { error }\end{array}$ & $\begin{array}{l}\text { Standardized } \\
\text { regression coefficient }\end{array}$ & t value & OR & P-value \\
\hline Age & 3.581 & 1.746 & 0.221 & 2.477 & 1.723 & 0.014 \\
\hline Starting time of postoperative activity & 4.192 & 1.911 & 0.248 & 2.531 & 2.285 & 0.024 \\
\hline Peritoneal drainage tube indwelling time & 1.335 & 0.894 & 0.072 & 1.974 & 1.644 & 0.012 \\
\hline Blood potassium level & 4.543 & 1.821 & 0.365 & 2.598 & 0.710 & 0.032 \\
\hline Sleep disorder & 3.461 & 1.579 & 0.184 & 2.387 & 1.542 & 0.027 \\
\hline Fasting and fluid deprivation time & 2.345 & 1.164 & 0.087 & 2.024 & 1.797 & 0.028 \\
\hline Social support & -4.926 & 2.102 & -0.429 & -4.093 & 0.668 & 0.016 \\
\hline
\end{tabular}

The data was analyzed by multivariate linear regression analysis.

Table V. Multivariate analysis on the first exhaust time of gastrointestinal tumor patients after laparoscopic surgery.

\begin{tabular}{lcccrrr}
\hline Variable & $\begin{array}{c}\text { Regression } \\
\text { coefficient }\end{array}$ & $\begin{array}{c}\text { Standard } \\
\text { error }\end{array}$ & $\begin{array}{c}\text { Standardized } \\
\text { regression coefficient }\end{array}$ & t value & OR & P-value \\
\hline Age & 5.218 & 1.733 & 0.145 & 3.281 & 1.511 & 0.029 \\
Starting time of postoperative activity & 8.273 & 2.917 & 0.162 & 3.012 & 1.723 & 0.004 \\
Peritoneal drainage tube indwelling time & 4.927 & 1.873 & 0.392 & 2.327 & 2.201 & 0.032 \\
Blood potassium level & 7.281 & 2.984 & 0.131 & 2.381 & 0.706 & 0.028 \\
Sleep disorder & 6.261 & 2.371 & 0.119 & 2.273 & 1.348 & 0.031 \\
Fasting and fluid deprivation time & 6.827 & 2.381 & 0.138 & 2.641 & 1.644 & 0.017 \\
Social support & -12.47 & 2.197 & -0.672 & -6.22 & 0.678 & $<0.001$ \\
\hline
\end{tabular}

The data was analyzed by multivariate linear regression analysis.

Table VI. Multivariate analysis on the first defecation time of gastrointestinal tumor patients after laparoscopic surgery.

\begin{tabular}{lcccrrr}
\hline Variable & $\begin{array}{c}\text { Regression } \\
\text { coefficient }\end{array}$ & $\begin{array}{c}\text { Standard } \\
\text { error }\end{array}$ & $\begin{array}{c}\text { Standardized } \\
\text { regression coefficient }\end{array}$ & t value & OR & P-value \\
\hline Age & 0.092 & 0.024 & 0.047 & 2.136 & 1.696 & 0.034 \\
Starting time of postoperative activity & 0.289 & 0.039 & 0.184 & 3.874 & 1.723 & 0.004 \\
Peritoneal drainage tube indwelling time & 0.078 & 0.028 & 0.063 & 2.486 & 1.511 & 0.032 \\
Blood potassium level & 0.301 & 0.043 & 0.261 & 4.992 & 2.286 & $<0.001$ \\
Sleep disorder & 0.382 & 0.052 & 0.312 & 4.283 & 0.294 & 0.002 \\
Fasting and fluid deprivation time & 0.248 & 0.0398 & 0.146 & 3.345 & 0.670 & 0.014 \\
Social support & -0.048 & 0.025 & -0.062 & -2.351 & 1.357 & 0.024 \\
\hline
\end{tabular}

The data was analyzed by multivariate linear regression analysis.

abdominal pain and distension and GIR were reduced in patients aged below 40 years compared to patients more than 40 years $(\mathrm{P}<0.05)$. With the starting time of postoperative activity $\leq 3$ days, the recovery time of bowel sound and the time to the first defecation/exhaustion were shortened, and abdominal pain and distension and GIR were reduced $(\mathrm{P}<0.01)$. With the peritoneal drainage tube indwelling time $\leq 7$ days, the recovery time of bowel sound and the time to the first postoperative defecation/exhaustion were shortened, and abdominal pain and distension and GIR were reduced $(\mathrm{P}<0.05)$. With normal serum potassium level, the recovery time of bowel sound and time to the first postoperative defecation/exhaustion were shortened, and abdominal pain and distension and GIR were reduced $(\mathrm{P}<0.01)$. For patients without sleep disorder, recovery time of bowel sound, and time to the first postoperative defecation/ exhaustion were shortened, and abdominal pain and distension and GIR were reduced $(\mathrm{P}<0.01)$. With postoperative fasting and fluid deprivation time $\leq 5$ days, the recovery time of bowel 
sound, and time to the first postoperative defecation/exhaustion were shortened, and abdominal pain and distension and GIR were reduced $(\mathrm{P}<0.05)$. With the increase of social support, the recovery time of bowel sound, and time to the first postoperative defecation/exhaustion were shortened, and abdominal pain and distension and GIR were reduced $(\mathrm{P}<0.05)$.

Multivariate analysis on recovery of gastrointestinal tumorpatients after laparoscopic surgery. The recovery time of bowel sound after operation and the time to the first postoperative defecation/exhaustion were set as dependent variables, and age, starting time of postoperative activity, peritoneal drainage tube indwelling time, blood potassium level, sleep disorder, fasting and fluid deprivation time and social support level were set as independent variables to perform multiple linear regression. As shown in Table IV, the recovery time of bowel sound after malignant gastrointestinal tumor surgery and time to the first postoperative defecation/exhaustion were affected by postoperative fasting and fluid deprivation time, starting time of postoperative activity, peritoneal drainage tube indwelling time, postoperative blood potassium level, sleep disorder and social support. Three factors including social support, postoperative blood potassium level, and postoperative activity time had a great influence on bowel sound recovery time $(\mathrm{P}<0.001,0.028,0.004)$; social support, peritoneal drainage tube indwelling time $(\mathrm{ORP}=0.032)$ and postoperative activity time had a great impact on the time of first discharge $(\mathrm{P}<0.001$, $0.005,0.031$ ); sleep disorders, blood potassium levels and time of first activity had a great impact on the first time of defecation $(\mathrm{P}=0.002,<0.001,0.004)$ (Tables V and VI).

\section{Discussion}

Gastrointestinal tumor is one of the chronic diseases with a relatively high and increasing incidence in China (20). Our study showed that age, starting time of postoperative activity, peritoneal drainage tube indwelling time, blood potassium level, sleep disorder, fasting and fluid deprivation time and social support level have significant influences on recovery of patients after operation.

Results of univariate analysis indicated that when patients were aged $\leq 40$ years, the recovery time of bowel sound, and time to the first postoperative defecation/exhaustion were shortened, and abdominal pain and distension and GIR were reduced. With the increase of age, compensatory ability of all organs in the body is weakened, immune function is decreased, and the recovery of gastrointestinal function will be slowed down (21). Combined with the decrease of muscular tension and insufficient bedridden activity, recovery time of defecation function will be prolonged, the function of gastrointestinal peristalsis will be weakened, and the recovery time of exhaust will be prolonged. However, the results of multivariate analysis revealed that aging is not the main influence factor, possibly due to the specific age distribution of the patients included in this study. Actually, the majority of patients with gastrointestinal cancer are in their middle or advanced age, which may weaken the effects of aging (22). Multivariate analysis showed that early postoperative ambulation, early removal of celiac drainage tubes, timely replacement of potassium, higher quality of sleep, and satisfactory social support can shorten postoperative bowel sound recovery time, time of first discharge or defecation, so as to improve postoperative gastrointestinal function. Multivariate analysis showed that the starting time of postoperative activity is closely associated with recovery time of bowel sound and time to the first postoperative defecation/exhaustion. The reason may be that the early passive activities in bed such as slapping back and turning over can accelerate metabolism, stimulate sympathetic nerve, promote blood circulation and promote the recovery of gastrointestinal function, and the later out-of-bed activity is also beneficial to the recovery of muscular tension, thus further promoting the recovery of gastrointestinal function, which is also conducive to the adjustment of mental state (23). Multivariate analysis indicated that the level of serum potassium is closely related to the time to the first defecation and recovery time of bowel sound blood potassium level in the body of patients; this level can be reduced by gastrointestinal decompression, abdominal drainage tube and long-term fasting and fluid deprivation, and the low level of blood potassium inhibits the excitability of smooth muscle cells, leading to the loss of contractile function of gastrointestinal smooth muscle, resulting in abdominal distension and even intestinal paralysis (21). On one hand, abdominal cavity drainage tube can completely drain the errhysis and seepage in abdominal cavity, reduce the incidence of inflammation, fever and abdominal pain, and promote recovery of the function of the gastrointestinal tract. On the other hand, nature of drainage fluid also reflect the condition of abdominal cavity and anastomosis; however, long-term stay of peritoneal drainage tube may lead to abdominal infection, intestinal obstruction or incisional hernia complications, which is harmful for the recovery of gastrointestinal function.

The study by Shang (24) compared the effects of different gastrointestinal decompression methods on postoperative gastrointestinal function recovery, indicating that negative natural voiding decompression is more beneficial to the recovery of gastrointestinal function and the shortening of hospitalization time compared with the continuous suction decompression. The study by Li et al (25) revealed that somatostatin can effectively promote the recovery of postoperative gastrointestinal function and ameliorate the prognosis of elderly patients with gastrointestinal cancer.

Our study also has some shortcomings. We excluded patients with mental illness and disorders to improve the reliability of our data. However, social support and sleep disorders may affect the postoperative recovery of patients with mental illness or disorder. Our future study will focus on those patients. BMI, TMN staging, and surgical methods performed in the study are unlikely to be identical. These factors may also affect the recovery of patients to some extent, but were not discussed in this study. We will solve these problems in our future studies.

In conclusion, some methods are beneficial to the recovery of gastrointestinal function to a certain extent and shorten the hospitalization time, including the removal of peritoneal drainage tube, timely potassium supplementation, recovery of diet as soon as possible and appropriate bedside activities.

\section{Acknowledgements}

Not applicable. 


\section{Funding}

No funding was received.

\section{Availability of data and materials}

The datasets used and/or analyzed during the present study are available from the corresponding author on reasonable request.

\section{Authors' contributions}

JS conceived and designed the study. SL and YW were responsible for the collection and analysis of the data. JS and LZ interpreted the data and drafted the manuscript. JS and SL revised the manuscript critically for important intellectual content. All authors read and approved the final study.

\section{Ethics approval and consent to participate}

The study was approved by the Ethics Committee of Dalian Central Hospital (Dalian, China). Signed informed consents were obtained from the patients or the guardians.

\section{Patient consent for publication}

Not applicable.

\section{Competing interests}

The authors declare that they have no competing interests.

\section{References}

1. Mignogna MD, Fedele S and Lo Russo L: The World Cancer Report and the burden of oral cancer. Eur J Cancer Prev 13: 139-142, 2004.

2. Mythen MG: Postoperative gastrointestinal tract dysfunction. Anesth Analg 100: 196-204, 2005.

3. Nakazawa K, Tanaka R, Kametani N, Hirakawa T, Kato Y, Komoto M, Yamagata S, Kanehara I, Ako E, Yamada N, et al: Multidisciplinary therapy for advanced gastric cancer with liver and brain metastases. Gan To Kagaku Ryoho 42: 2009-2011, 2015 (In Japanese).

4. Chen L, Xi H and Shen W: Multidisciplinary therapy for gastric cancer with liver metastasis. Zhonghua Wei Chang Wai Ke Za Zhi 17: 101-104, 2014 (In Chinese).

5. Fujisaki J, Omae M, Shimizu T, Morishige K, Miyamoto Y, Taniguchi C, Horiuchi Y, Yoshio T, Ishiyama A, Hirasawa T, et al: Minimally invasive surgery for the treatment of adenocarcinoma of the esophagogastric junction. Nihon Geka GaKKai Zasshi 116 : 29-34, 2015 (In Japanese).

6. Sista F, Pessia B, Abruzzese V, Cecilia EM, Schietroma M, Carlei F and Amicucci G: Twelve years of gastric GIST A retrospective study of laparoscopic and open approach. Ann Ital Chir 86: 349-356, 2015.

7. King PM, Blazeby JM, Gupta J, Alderson D and Moorghen M: Upper gastrointestinal cancer pathology reporting: A regional audit to compare standards with minimum datasets. J Clin Pathol 57: 702-705, 2004

8. Chen C, Huang P, Lai L, Luo C, Ge M, Hei Z, Zhu Q and Zhou S: Dexmedetomidine improves gastrointestinal motility after laparoscopic resection of colorectal cancer: A randomized clinical trial. Medicine (Baltimore) 95: e4295, 2016.
9. Mizuno M, Kataoka J and Oishi F: Relationship between the physical and psychosocial conditions of postoperative gastrointestinal cancer patients and their responses to an informational material. Asia Pac J Oncol Nurs 4: 53-60, 2017.

10. Zhang L, Xu A, Han W, Wei Z, Xiong M, Yang W and Hu K: Effect of body mass index on postoperative outcomes in patients with gastric cancer. Zhonghua Wei Chang Wai Ke Za Zhi 19: 296-299, 2016 (In Chinese).

11. Kwon SJ: Evaluation of the 7th UICC TNM staging system of gastric cancer. J Gastric Cancer 11: 78-85, 2011.

12. Michelet D, Andreu-Gallien J, Skhiri A, Bonnard A, Nivoche Y and Dahmani S: Factors affecting recovery of postoperative bowel function after pediatric laparoscopic surgery. J Anaesthesiol Clin Pharmacol 32: 369-375, 2016

13. Husslein H, Franz M, Gutschi M, Worda C, Polterauer S and Leipold H: Postoperative gum chewing after gynecologic laparoscopic surgery: A randomized controlled trial. Obstet Gynecol 122: 85-90, 2013.

14. Benlice C, Costedio M, Kessler H, Remzi FH and Gorgun E: Comparison of straight vs hand-assisted laparoscopic colectomy: An assessment from the NSQIP procedure-targeted cohort. Am J Surg 212: 406-412, 2016.

15. Kafali H, Duvan CI, Gözdemir E, Simavli S, Onaran Y and Keskin E: Influence of gum chewing on postoperative bowel activity after cesarean section. Gynecol Obstet Invest 69: 84-87, 2010.

16. Baber KF, Anderson J, Puzanovova M and Walker LS: Rome II versus Rome III classification of functional gastrointestinal disorders in pediatric chronic abdominal pain. J Pediatr Gastroenterol Nutr 47: 299-302, 2008.

17. Small AJ, Sutherland SE, Hightower JS, Guarner-Argente C, Furth EE, Kochman ML, Forde KA, Bewtra M, Falk GW and Ginsberg GG: Comparative risk of recurrence of dysplasia and carcinoma after endoluminal eradication therapy of high-grade dysplasia versus intramucosal carcinoma in Barrett's esophagus. Gastrointest Endosc 81: 1158-66.e1, 4, 2015.

18. Gelaye B, Lohsoonthorn V, Lertmeharit S, Pensuksan WC, Sanchez SE, Lemm S, Berhane Y, Zhu XT, et al: Construct validity and factor structure of the Pittsburgh sleep quality index and Epworth sleepiness scale in a multi-national study of African, South East Asian and South American College students. Pittsburgh sleep quality index (PSQI) and Epworth Sleepiness Scale (ESS) subscale-total scale correlations according to country: PLoS One 9: e116383, 2014.

19. Xu LZ, Qiu GQ, Chu XJ, Sun Y and Chen YQ: Investigation on social support and treatment compliance of elderly cancer patients in empty-nest family. Occup Health (Lond) 29: 1099-1100, 2013.

20. Song X, Song H, Li HW, Guo RY, Zhang XQ, Jia SF, Wang WL, Bai W and Wang F: Prognostic analysis of 53 patients with multiple primary upper gastrointestinal cancer. Cancer Res Clin 27: 44-46, 2015.

21. Wang G, Jiang ZW, Xu J, Gong JF, Bao Y, Xie LF and Li JS: Fast-track rehabilitation program vs conventional care after colorectal resection: A randomized clinical trial. World J Gastroenterol 17: 671-676, 2011.

22. Jung HS, Park YK, Ryu SY and Jeong O: Laparoscopic total gastrectomy in elderly patients ( $\geq 70$ years) with gastric carcinoma: A retrospective study. J Gastric Cancer 15: 176-182, 2015.

23. Hu GJ, Li XM, Tan MX and Jiang NN: A special exercise program is helpful for postoperative recovery of gastrointestinal function in gynecologic malignancy patients. J Nurs Sci 28: 13-15, 2013.

24 . Shang J: Influence on gastrointestinal function recovery of gastric surgery treated different ways gastrointestinal decompression. Chin Mod Doct 53: 74-75, 2015.

25. Li F, Yao XQ, Sun ZH, Yang G and Tang W: Effect of somatostatin on the recovery and prognosis of gastrointestinal function in old patients after gastrointestinal tumor surgery. Jianyan Yixue Yu Linchuang 10: 1633-1634, 2013 (In Chinese).

(i) $(5)$ This work is licensed under a Creative Commons Attribution-NonCommercial-NoDerivatives 4.0 International (CC BY-NC-ND 4.0) License. 